Pedagogía y Saberes No. 51

Universidad Pedagógica Nacional

Facultad de Educación. 2019. pp. 113-132

\title{
Educación religiosa pública y no confesional*
}

Artículo de reflexión

Public and Non-Denominational Religious Education Educação religiosa pública e não confesional

Leonardo Tovar Bernal**

Para citar este artículo:

Tovar, L. (2019). Educación religiosa pública y no confesional. Pedagogía y Saberes, 51, 113-132.

* Este escrito hace parte de la tesis presentada a la Facultad de Ciencias Humanas del Colegio Mayor de Nuestra Señora del Rosario-Universidad del Rosario para optar al título de Magíster en Filosofía.

** Profesor de la Secretaría de Educación del Distrito Capital. Magister en Filosofía del Colegio Mayor de Nuestra Señora del Rosario-Universidad del Rosario.

Correo electrónico: leonardotovarbernal@yahoo.es.

Código ORCID: orcid.org/0000-0002-7299-7917. 


\title{
Resumen
}

¿Qué sitio le corresponde a la educación religiosa en la escuela pública en Colombia? ¿Es compatible una enseñanza religiosa que privilegie un credo particular en un Estado que se muestra como pluralista? Este artículo de reflexión intenta responder a estos interrogantes a partir de tres momentos. Primero, se exponen las características actuales del fenómeno religioso y se trata el pluralismo como un problema político y teológico. Después, se compendia la legislación liberal colombiana que favorece el pluralismo y se analizan algunos programas de la llamada Enseñanza Religiosa Escolar. Por último, se revisan cuatro textos de instrucción religiosa y se presenta una propuesta no confesional sobre el lugar que podría ocupar la enseñanza religiosa en la escuela pública.

\section{Palabras clave}

enseñanza religiosa; escuela pública; pluralismo; confesional; religión

\begin{abstract}
What is the place of religious education in the public school in Colombia? Is religious teaching that privileges a particular creed compatible with a State that shows itself as pluralistic? In this reflection, we will try to answer these questions from three moments. First, the current characteristics of the religious phenomenon are discussed, and pluralism is treated as a political and theological problem. Subsequently, the Colombian liberal legislation that favors pluralism is condensed, and some programs of the so-called School Religious Teaching are analyzed. Finally, we review four texts of religious instruction and introduce a non-confessional proposal about the place that religious teaching could occupy in the public school.
\end{abstract}

\section{Key words}

religious teaching; public school; pluralism; confessional; religion

\section{Resumo}

Qual é o lugar da educação religiosa na escola pública na Colômbia? É compatível um ensino religioso que privilegia um credo particular num Estado que é mostrado como pluralista? Este artigo de reflexão, tenta responder a essas questões a partir de três momentos. Primeiro, são expostas as características atuais do fenômeno religioso tratando o pluralismo como um problema político e teológico. Posteriormente, é condensada a legislação liberal colombiana que favorece o pluralismo e analisam-se algumas propostas do chamado Ensino Religioso Escolar. Finalmente, são revisados quatro textos de instrução religiosa e é apresentada uma proposta não-confesional sobre o lugar que o ensino religioso poderia ocupar na escola pública.

\section{Palavras-chave}

ensino religioso; escola pública; pluralismo; confessional; religião 


\section{Religión y pluralismo}

\section{Configuración religiosa en la actualidad}

Quienes han estudiado el fenómeno religioso a partir de posiciones que cuestionan o van más allá de las tesis secularistas parecieran mostrar un relativo consenso sobre la importancia de la religión ${ }^{1}$ en las sociedades contemporáneas: el creyente conduce su existencia diaria desde la fe y la religión disfruta de un notable "potencial de realidad" (Habermas, 2006, p. 134), es decir, es significativa en términos de los motivos y "autointerpretaciones" (Habermas, 2006, p. 134) de las personas en su diaria realización social (Berger, 2006). En el espacio político lo religioso continúa con una influencia apreciable, pese a la separación constitucional establecida por las legislaciones liberales. La religión ha sobrevivido no solo a lo más privado de la esfera social sino a lo más público del Estado (Tschannen, 1991). Las tradiciones religiosas siguen exhibiendo cierta actualidad, aun de una forma "más intensa que la metafísica” (Habermas, 2006, p. 150).

1 Se concibe la religión como un complejo sistema de características que, de acuerdo a la forma que tomen en la creencia, se asocian a unas prácticas simbólicas; unos determinados puntos de vista sobre el mundo; unas escrituras que respaldan la fe; un sistema escatológico; unas figuras relevantes, algunas veces presentadas como santos, guías espirituales, etc.; unas presunciones morales, así como unas pretensiones de verdad; una estructura sustentada en el "término híbrido" de "salvación/liberación" (Hick, 2004, p. 10); o una "Realidad Última" (Hick, 2004, p. 11). En este modo de pensar la religión, tales rasgos no son "estrictamente" comunes a la totalidad de las religiones, pero hay distintivos que se "distribuyen" "esporádicamente" (Hick, 2004, p. 4) en los diversos grados que conforman las religiones, lo cual, en su conjunto, llega a constituir una "family-resemblance" (Hick, 2004, p. 4); ello hace que se distingan de otras "familias" (Hick, 2004, p. 4). Aquí no se trata de definir una "esencia común" (Hicks, 2004, p. 4) a todas las tradiciones, pero sí de reconocer que están compuestas por una "complejidad continua" (Hick, 2004, p. 4) de semejanzas y disimilitudes, donde cada una de esas características alcanza diferentes representaciones en el interior de la religión, y es interpretada de variadas maneras, que no pueden extrapolarse, mas sí describirse (Hick, 2004).

Como práctica religiosa se entenderá todo el amplio y diverso grupo de manifestaciones humanas relacionadas con las acciones, los procedimientos o las rutinas que se enfocan en reverenciar, sostener y difundir una creencia: la veneración, los ritos, los sacrificios, las oraciones, los rituales de iniciación, la meditación, las fiestas conmemorativas, la música, el arte, la arquitectura, etc. Schwimmer señala que las prácticas religiosas varían de acuerdo con el "grado en que explicitan la ideología de la que reciben 'sentido'” (Schwimmer, 1982, p. 75). De tal manera es posible encontrar, por un lado, "sistemas de gestos", manipulación de los "objetos de culto", utilización de "indumentos y parafernalia" (p. 75); por el otro, las "ofrendas y sacrificios", las "reglas sagradas" sobre el espacio y el tiempo o los "objetos decorativos y artísticos" (p. 75).
Para muchos individuos y sociedades lo religioso juega un papel destacado en la subjetividad, la cosmovisión, las relaciones entre ciudadanos y la política. Incluso, para pensadores como Habermas (2006), las religiones aportan "potenciales semánticos valiosos" idóneos para "inspirar" (p. 150) al conjunto social.

Lo religioso, en la actualidad, es complejo y no es un proceso uniforme y acabado. Implica determinadas particularidades que se moldean de acuerdo con la sociedad en donde tiene lugar. Por ejemplo, en Estados Unidos se manifiesta un fenómeno que tendería hacia una "revitalización política de la religión" (Habermas, 2006, p. 122); en diversas partes del planeta se ha exteriorizado un progresivo crecimiento del islam (Gómez, 2014, p. 34); en Latinoamérica, África y Asia se vive una fuerte influencia de la "pentecostalización" (Bastian, 1997, p. 144). ${ }^{2}$

Se trata de una época caracterizada por una suerte de reconfiguración religiosa que se presentó después del proceso de secularización ocurrido en el periodo moderno. ${ }^{3}$ Grosso modo, este fenómeno de secularización mostró una serie de transformaciones en lo religioso y en las condiciones de la creencia. Se destacan, por un lado, el menoscabo en el privilegio y exclusividad "cosmovisional” (Gómez, 2014, p. 32) de las instituciones religiosas tradicionales; por el otro, el hecho de que la justificación de la fe se deslizó desde la verdad proferida por la autoridad externa hacia la subjetividad de los individuos. La secularización en este escenario no se entendería como la desaparición de la religión sino como una nueva forma de creer propia de la modernidad, en la que la creencia se constituyó en una opción voluntaria y subjetiva (Gómez, 2014). La religión aquí declararía su naturaleza "peculiarmente moderna" (Berger, 2006 p. 164), donde los creyentes no estarían sujetos a la coerción y la aceptarían de manera consciente. Se establece como una cuestión de "elección" o "preferencia", cuyo rasgo común y unificador de las comunidades religiosas pierde importancia. Esto mostraría un presunto abandono de la tarea tradicional de

2 Sus rasgos más notables son el énfasis en la alabanza como acto "emocional de afirmación" (Bastian, 1997, p. 144), que rebasa, incluso, el poder mismo del texto; el predominio de la "glosolalia" o "hablar en lenguas" que funciona como un lenguaje enfocado a generar una emoción tal, que el feligrés llegue al "paroxismo y alcance una divina rapsodia" (p. 144); el influjo de la "práctica taumatúrgica de los milagros" y la "sanidad divina" (p. 145).

3 Autores como Peter Berger hablan de "des-secularización del mundo", mientras que Jürgen Habermas se refiere a este fenómeno como "sociedad postsecular" (Gómez, 2014, p. 18). 
la religión, que consiste en ofrecer un conjunto de significados compartidos por los integrantes de la sociedad (Berger, 2006). ${ }^{4}$

La creencia, entonces, en la época contemporánea exhibe ciertas características relacionadas con el "fundamentalismo", la "religiosidad difusa" y la "religión secular" (Gómez, 2014). La "religión secular" o "religión profana" es uno de los modos que adoptaría la fe, cuyas expresiones más evidentes tendrían que ver con los distintos comportamientos de la vida cotidiana que involucran un claro contenido religioso - el entretenimiento, el trabajo, etc.- - Es posible observar cómo las acciones o los gestos de la "vida profana" (Mardones, 1994, p. 91) adoptan ciertas maneras de lo sagrado. Esta influencia religiosa se presenta en los más diversos ámbitos del deporte, el cuerpo, la belleza, la sexualidad; aun en esferas vinculadas con la música, la política, los negocios o los cultos a la naturaleza y la madre tierra (Mardones, 1994). Prácticas que enseñan una adoración muy semejante a las específicamente sacras y en las que "se crean rituales, se elevan mitos o ídolos y nacen cultos" (Mardones, 1994, p. 111). En la música, por ejemplo, en algunas manifestaciones surge un gran ritualismo caracterizado por una asistencia masiva a una ceremonia - el concierto-, el culto al ídolo, las afinidades en la manera de vestir, la identidad colectiva y toda una serie de conductas tendientes a constituir un "culto grupal" (p. 92). El "resurgir de la gran madre tierra" (p. 106) es otro campo donde los límites entre lo profano y lo sagrado parecen confundirse. Determinado por una especie de culto a la naturaleza, que alcanza los rincones más profundos de la "ideología y las opciones existenciales" (p. 107), se alza, con una devoción propia de las prácticas religiosas, una veneración al retorno a la "vida sencilla, modesta, elemental" (p. 107), revelándose el "sabor vital de la comunión con la naturaleza en las formas arcaicas” (p. 107). En esta forma de "religión secular", el "culto a Gaia" (p. 107) se despliega en su máxima expresión.

El "fundamentalismo" se caracterizaría por: 1) el hecho de que la creencia recae en la "afirmación de una autoridad religiosa fuerte" (Gómez, 2014), definida por la legitimidad que ofrecen la institución religiosa, los textos sagrados, la fuerza que ejerce la autoridad de la tradición y la fe hacia los dirigentes religiosos; 2) el "exclusivismo con respecto a las pretensiones de verdad" (Gómez, 2014), que muestra la religión profesada como la única verdadera que redime, salva, libera o ilumina; es decir, que las otras manifestaciones religiosas estarían equivocadas; 3) el "literalismo en la interpretación de los textos

4 Este es un rasgo de lo que Peter Berger ha denominado "individualización" (Berger, 2006, p. 164). sagrados" (Gómez, 2014), que emana de la aseveración de que la palabra de Dios se manifiesta de manera directa en las páginas de las escrituras, y descarta las interpretaciones posibles o cualquier licencia hermenéutica; 4) la "pasión religiosa" (Gómez, 2014), justificada en la certeza incuestionable surgida del libro sagrado y la autoridad religiosa que hacen de esta forma una veta de fanatismo y pérdida de cualquier actitud crítica frente a la creencia; 5) la "configuración de comunidades de fe de carácter sectario" (Gómez, 2014), donde una doctrina es la escogida y la única que posee el monopolio de la verdad, se instauran cofradías que parecen estar aisladas del mundo, y disponen de lo necesario para protegerse, tanto de los que están por fuera del círculo, como de sus amenazas; encarnadas, comúnmente, en el laicismo, la inmoralidad y la ciencia.

El término de "religiones difusas" se aplica a un amplio, variado y sincrético grupo de credos y prácticas que presentan rasgos más o menos comunes: 1) La "desinstitucionalización de la creencia" (Gómez, 2014) se reconoce por la falta de pertenencia o identificación "fuerte" con una institución religiosa y por la participación en diversas prácticas - p. ej. un católico que va a misa, toma yagé, realiza yoga y se rige por el horóscopo-. En otras palabras, el "nuevo" creyente establece su "propio cocktail" (Tschannen, 1991, p. 401) de cristianismo, hinduismo y astrología. 2) El "pluralismo superficial y ocultador de la diferencia" se refiere a la aseveración de que las diversas religiones y creencias aluden a las mismas realidades divinas, pero con diferentes nombres, y guían hacia idénticos propósitos (Gómez, 2014); aquí el asunto radicaría en el hecho de que en cada una de ellas son nombrados de manera distinta. 3) La "libertad hermenéutica" y el "subjetivismo radicales" (Gómez, 2014) se muestran en la privatización que ha propiciado que el individuo se constituya en el responsable principal de proveer sentido a sus creencias, donde la subjetividad se instituye en la autoridad religiosa por excelencia que legitima el credo. 4) La "emocionalidad" y la "prioridad de la experiencia directa" (Gómez, 2014) se caracterizan por la idea de que la veracidad de la creencia se explica en la búsqueda y experimentación directa del sujeto que siente y prueba la sanación, la liberación o el poder de lo sagrado. Otro atributo de las "religiones difusas" se manifiesta en 5) la "itinerancia cosmovisional" (Gómez, 2014), es decir, el movimiento permanente de la creencia, el cual hace que esta se encuentre abierta a la modificación constante y a la reconfiguración de sus fundamentos.

Con este breve repaso por las formas que ha adoptado el fenómeno religioso en la actualidad se pretende hacer énfasis en lo siguiente: en las sociedades 
contemporáneas se revela una significativa influencia religiosa, cuyas manifestaciones muestran un complejo entramado que está lejos de ser un proceso homogéneo. Sugerir la fuerte presencia en la actualidad del asunto religioso permite señalar: 1) la problematización de las aseveraciones que presagiaban un progresivo ocaso de la religión, debido a la creciente racionalización del mundo; 2) el hecho de que pese a la racionalización del mundo contemporáneo la religión se constituye en un elemento influyente en las esferas tanto pública - política, educación, economía - como privada - visiones de mundo, proyectos de vida-; 3) que la religión no se ha confinado al ámbito interno del individuo sino que sigue vigente en el espacio de lo público.

\section{El pluralismo como problema político}

La interpelación por el lugar que le corresponde a la enseñanza de la religión en la escuela pública remite al pluralismo, en tanto no podría ser posible privilegiar un credo en el sistema educativo estatal de una nación que se inscribe en el liberalismo político y se confiesa como pluralista a costa de la convivencia en condiciones de justicia exigida por este principio. Con respecto a esta noción, podría sintetizarse el problema religioso en la pregunta esbozada por John Rawls: “¿Cómo es posible que exista a través del tiempo una sociedad justa y estable de ciudadanos libres e iguales que, sin embargo, sigan profundamente divididos por doctrinas razonables, religiosas, filosóficas y morales?" (Rawls, 1995, p. 66).

El liberalismo político no es un conjunto uniforme de suposiciones concluidas e inmunes a la controversia; ello le confiere un carácter heterogéneo e inacabado. De la misma manera, como cualquier teoría que pretenda organizar la sociedad, el liberalismo político reposa en postulados y conceptos que lo hacen posible. Dentro de estas nociones, el pluralismo se erige como un presupuesto constitutivo y fundamental. En ese sentido, se sugieren dos tesis sobre las que se basará el análisis del presente trabajo: 1) el orden político colombiano descansa sobre la doctrina del liberalismo ${ }^{5}$ y 2) el pluralismo es un principio fundamental de este sistema.

5 En general, el Estado colombiano descansa sobre preceptos del "liberalismo clásico" (Uprimny y Rodríguez, 2006, p. 6) y el "constitucionalismo social" (p. 6). Presenta un sistema jurídico regido por una carta constitucional que subordina los actos del Estado y la sociedad. Esta constitución, la de 1991, se enmarca en el "constitucionalismo social" como una estructura "normativa y valorativa" (p. 6) que reconoce los "derechos liberales" y los "derechos sociales" (p. 6), además de otorgarles poder normativo. Así, muestra la "distinción clásica" entre los "derechos económicos de libertad" y los "derechos sociales
No se pretende desestimar las controversias que sobre 1) y 2) existan, pero no es objeto de este escrito abordarlas y profundizar en ellas. No se ahondará en 1) y se asumirá como dado; con respecto a 2), también se admitirá como un hecho, pero se intentará examinar lo que el pluralismo significa como concepto imprescindible, tanto para el liberalismo político, como para un Estado que justifique su ordenamiento en esta teoría.

John Rawls (1995) distingue entre el "pluralismo como tal" y el "pluralismo razonable". Al defender este último, Rawls presupone que una democracia cualquiera se caracterizaría, en principio, por la presencia de un "pluralismo como tal", pues concurren diversas doctrinas que podrían concebirse como "irrazonables" (p. 79). Y así como confluyen estas creencias "irrazonables", lo propio hacen otras que no lo son, denominadas como "doctrinas comprensivas razonables" (Rawls, 1995). Con el término doctrinas "irrazonables" el autor se refiere a las que, por lo menos, presentarían las siguientes características: 1) afirman sus postulados de modo no razonable, es decir, de una manera "ciega o caprichosa"; 2) establecen condiciones mínimas apropiadas para los objetivos del liberalismo político y 3 ) atribuyen un peso excesivo a los propios valores sobre otros que podrían ser más adecuados en términos de una organización social democrática. Nótese que no se trata de considerar como doctrinas "irrazonables" a aquellas que "no poseen fundamentos sólidos apoyados en aspectos claros de lo razonable" (p. 79), lo cual hace que la delimitación del concepto presente un carácter complejo y de difícil resolución.

de prestación" (p. 6). Entre los primeros, se destacan aquellas garantías que buscan "proteger" la propiedad, el mercado y la "autonomía privada" (p. 6); mientras que los segundos tienen que ver con las políticas públicas de suministro de bienes y servicios como vivienda, salud y educación (Uprimny y Rodríguez, 2006).

En teoría, el ordenamiento colombiano evidencia similitudes muy características del liberalismo político. Tiene lugar la llamada separación del poder público en tres poderes (judicial, legislativo y ejecutivo). Los ciudadanos a partir de elecciones eligen a sus representantes. También manifiesta una escisión entre el Estado, quien concentra la fuerza para hacer cumplir derechos y deberes, y la sociedad, cuya agrupación de individuos se hace acreedora a derechos naturales como la vida o la libertad. En cuanto al papel del Estado, en lo económico no interfiere en la planificación de la economía, sino se acoge a la regulación de la oferta y demanda del mercado, donde el respeto por la propiedad privada se constituye en un derecho inviolable; asimismo, no se inmiscuye en los asuntos de los particulares, solo los hace cumplir mediante la ley. Con respecto al individuo, establece una normatividad que garantizarían su vida, su libertad, el desarrollo de su conciencia, su propiedad. En este sentido, divide estos derechos, según su naturaleza, en políticos, civiles y económicos. 
Por otro lado, para Rawls (1995) las "doctrinas comprensivas razonables" se distinguirían por: 1 ) constituirse, tanto en una acción de la razón teórica que de una forma congruente y equilibrada abarca las esferas religiosas, filosóficas y morales de la vida humana, como en una acción de la razón práctica que señala cuáles de sus postulados enseñan un valor superior dentro de la creencia y procede a resolver los posibles conflictos en los que estas puedan incurrir; 2) ordenar y definir las creencias que la componen con el objetivo de establecer una imagen inteligible del mundo; 3) hacer parte o ser el resultado de una doctrina o tradición de pensamiento que no se altera de modo inesperado, lo cual descubre que sus transformaciones se manifiestan progresivamente; ello no significa que las "doctrinas comprensivas razonables" tengan un carácter inmóvil e inmutable.

Después de delimitar el significado de las creencias "irrazonables" (p. 146) y las "doctrinas comprensivas razonables", Rawls (1995) establece que sin importar que las democracias se basen en un "pluralismo como tal" —creencias irracionales, insensatas o agresivas-, en una sociedad bien ordenada es necesario dar el paso al "pluralismo razonable". El objetivo de dicha sociedad bien ordenada sería encontrar un consenso de "doctrinas comprensivas razonables", y este acuerdo sería posible si se admite la noción del "pluralismo razonable". Además del hecho de que una sociedad bien ordenada se orienta a la consecución de un consenso entre "doctrinas comprensivas razonables", el "pluralismo razonable" se distinguiría del "pluralismo como tal" en tanto es el "resultado a largo plazo del trabajo de la razón humana en instituciones libres y durables" (p. 134) por llegar a arreglos entre integrantes de la sociedad. A diferencia del "pluralismo como tal", este "pluralismo razonable" no es la consecuencia de las circunstancias infortunadas de la vida humana.

En resumen, el "pluralismo razonable" se distingue del "pluralismo como tal", por lo menos, en que el primero contiene "doctrinas comprensivas razonables", demanda un consenso entre ellas y es producto del trabajo de la razón humana en instituciones libres y durables; mientras que el segundo es obra de las circunstancias infortunadas de la vida humana y contiene "doctrinas comprensivas no razonables, irracionales y hasta absurdas" (p. 12) que si no se contienen, pondrían en peligro la unidad y la justicia de la sociedad. Rawls define el "pluralismo razonable" como la existencia de "una pluralidad de doctrinas comprensivas razonables, pero incompatibles entre sí" (p. 12).
Aquí el "pluralismo razonable" se constituye en un aspecto de suma trascendencia para el liberalismo político. ¿En qué radica esa importancia? En su parte formal, este sistema "no preconiza ninguna doctrina específica, metafísica o epistemológica” (p. 35) y "tiene que ser imparcial (...) entre los diversos puntos de vista de las doctrinas comprensivas razonables" ( $\mathrm{p}$. 14), pues se trata de una sociedad democrática identificada por la diversidad de creencias comprensivas religiosas, filosóficas y morales, incompatibles entre sí, que carecen en el presente y el futuro del consenso general de la ciudadanía (Rawls, 1995). De tal manera que, la afirmación de un "pluralismo razonable" tendría que contemplar la búsqueda de un consenso, no una preferencia, entre la variedad de "doctrinas comprensivas razonables" que son inconciliables entre sí y que hacen parte de la sociedad.

Lo anterior suscita un problema para el liberalismo político y para cualquier Estado que fundamente su ordenamiento en este sistema. Rawls (1995) lo sintetiza en el interrogante citado al inicio de esta sección: “¿cómo es posible que exista a través del tiempo una sociedad justa y estable de ciudadanos libres e iguales que, sin embargo, sigan profundamente divididos por doctrinas razonables, religiosas, filosóficas y morales?" (p. 66). Un modo posible de abordarlo es a través del reconocimiento de la noción de "pluralismo razonable" como una diversidad de "doctrinas comprensivas razonables" incompatibles entre sí que deben encontrar un consenso. ¿De qué forma puede lograrse tal consenso? Según Rawls, en la medida en que el "pluralismo razonable" constituye una sociedad democrática, al liberalismo político le es necesario acercarse a las condiciones de posibilidad que consiguieran disponer de una "base pública" razonable sobre los asuntos políticos primordiales. Le competería tratar de diferenciar la perspectiva pública de otras no públicas, y advertir el porqué la "razón pública" adquiere una forma específica. En este punto se vincula la imparcialidad que le compete al liberalismo político en cuanto a las numerosas concepciones de las "doctrinas comprensivas razonables". La imparcialidad se configura al no amonestar, excluir o asumir como propias las aseveraciones formuladas por cada creencia. El liberalismo comprende que los juicios de veracidad de cada doctrina se hacen desde el punto de vista respectivo, donde cada una los construye a partir de lo que "ven como valores importantes" (p. 14-15). En este sentido, fijar la verdad de las sentencias de las "doctrinas comprensivas razonables" "no es asunto 
del liberalismo político" (p. 14-15), en tanto este lo entiende desde una concepción limitada y particular que se lo impide.

El consenso y la imparcialidad del liberalismo político no aspira al establecimiento de un juicio como verdadero, pues una "doctrina comprensiva razonable no puede asegurar la base de la unidad social, ni puede dar la capacidad de la razón pública en cuestiones políticas fundamentales" (Rawls, 1995, p. 137); no le es permitida la pretensión de "pensar que la verdad es solo una" (p. 79), por eso no se compromete con una "doctrina comprensiva razonable" específica. Se trata, más bien, de ordenar una concepción política de la justicia razonable que soporte el consenso entre las "doctrinas comprensivas razonables" y habilite la estabilidad de una sociedad constituida por un "pluralismo razonable". Así, es más apropiado referirse a una búsqueda de lo razonable que a la demanda por la verdad.

La pregunta por lo razonable consentiría la estabilidad y el compromiso con una concepción política que vincula ciertos "valores políticos" (p. 137), no todos. Ellos, a su vez, confieren una "base pública" a partir de unos principios fundados en la "razón práctica" y "unidos a concepciones de la sociedad y de la persona" (p. 137), que viabilizan el consenso entre las variadas "doctrinas comprensivas razonables" y la estabilidad de la sociedad democrática. Para Rawls, la existencia de un "pluralismo razonable" responde al problema del entendimiento público que asegure la permanencia de la sociedad democrática; a los asuntos que pudiesen originar más fraccionamientos de los esperados por la mera existencia de "doctrinas comprensivas razonables" que son incompatibles entre sí; a las "resistencias" (p. 157) y al debilitamiento de los principios de la cooperación social.

El pluralismo sería razonable no solo en la medida que podría constituirse en el "mejor modo" (Schmidt, 2014, p. 113) de contrarrestar los posibles excesos de las doctrinas incompatibles, sino porque equilibraría las fuerzas que desestabilizan a la sociedad y posibilitaría las circunstancias racionales indispensables para un orden legal admisible para todos (Schmidt, 2014). De modo que, el "pluralismo razonable" mediante la "razón secular" tendría la tarea de constituirse en un "filtro" para "traducir, interpretar y criticar" (p. 128) las creencias religiosas, sin que ello implique su exclusión del debate público. La idea de que el pluralismo mantenga a la sociedad estable pese a la existencia de diversas concepciones sobre el mundo es lo que le adjudica su carácter de razonable. Para un Estado que se constituye sobre los fundamentos del liberalismo y se presenta como pluralista, el pluralismo se constituye en una norma y en un bien que "asegura la paz social" y hace que la "sociedad se mantenga viva" (p. 113).

\section{El pluralismo como problema teológico}

El pluralismo no se circunscribe solo al espacio político, sino que también se constituye en un problema que afecta el campo mismo de las religiones. El asunto del pluralismo en lo religioso se traduce en un amplio panorama de conceptos y escuelas denominado Teología del Pluralismo Religioso -TPR- (Bonilla, 2011). Sin ahondar en las discusiones conceptuales que existen alrededor de la TPR, ${ }^{6}$ es pertinente precisar que su análisis se centrará en la teología ${ }^{7}$ cristiana (católica), en tanto es este sistema de creencias el que prevalece en la enseñanza pública colombiana.

Para algunos teóricos católicos ${ }^{8}$ es posible considerar el pluralismo como una característica de la sociedad contemporánea, que involucra una variedad de experiencias religiosas, iglesias, grupos de oración, capillas, etc. (Bonilla, 2011). Sin confinarse tan solo a la existencia de esta variedad, el pluralismo religioso también se constituiría como una consecuencia de un momento histórico en el que las religiones se conocen mejor entre sí y de una aparente disposición hacia el diálogo entre creencias. ${ }^{9}$ Utilizando una metáfora, en extremo idílica, de John Hick, José María Vigil describe por qué el pluralismo tiene lugar en la religión:

6 Por ejemplo, si la TPR hace parte de las teologías del genitivo - teología de la esperanza, teología política, teología de la revolución, etc.- (Bonilla, 2011) o si representa, más bien, un nuevo paradigma para la teología, en el sentido que le da Kuhn (Vigil, 2007).

7 El concepto de teología en este trabajo se entiende, en su sentido más amplio, como esa disciplina, inscrita en una creencia específica, que trata sobre los hechos, asuntos, razonamientos vinculados con Dios y su revelación. En el caso de la teología cristiana, esta "es decididamente una justificación racional de la verdad de la fe cristiana, una fe cuyo objeto es la realidad de Jesucristo y, por tanto, la realidad de Dios y también la del hombre" (Küng, 1989). Se trata de una teología fundada en los preceptos de una religión particular: la fe cristiana. Por otro lado, autores como Ferraro (2005) la entienden como aquella que, en lo fundamental, se encarga de tres asuntos. El primero tiene que ver con traducir y entender la revelación, con el objetivo de que se constituya en fundamento que ayude a los "problemas originados por la historia humana" (p. 31); aquí se intenta mostrar a la "fe ligada con la vida" (p. 31). El segundo concierne al hecho de "hacer comprensible" la revelación a partir de "todos los medios" y "posibilidades humanas" (p. 31): ciencias humanas o ciencias de la naturaleza. Finalmente, la teología se encargaría de buscar "nuevas respuestas" (p. 31) a los retos que el mundo impone a la creencia.

8 Dupuis (2000), Garay (2002), Geffré (2001), Vigil (2012).

9 Asimismo, autores como Torradeflot (1998) señalan que dentro de las circunstancias que motivaron el pluralismo religioso es posible considerar un "cierto sentimiento occidental de 
[...] desde su nacimiento, las religiones han venido peregrinando, por valles paralelos, cada una por el suyo, flanqueado por altas montañas que les impedían verse, cantando y alabando a Dios en una historia de amor entre Dios y su pueblo. Pero con el caminar por el valle, las montañas se han hecho cada vez menos altas, y llega un momento en que se hacen tan bajas que permiten ver a los otros pueblos, que venían peregrinando también por los otros valles, y que ahora desembocan en la planicie, y se encuentran alabando a Dios cada una con un pasado distinto, una lengua diversa, una concepción religiosa "inconmensurable" con las demás [...] En el mundo actual, ya están todas las religiones juntas, permanentemente ante todas las demás, a libre disposición de todos sus miembros. Las fuentes religiosas, como sus Sagradas Escrituras y su patrimonio simbólico se "despatrimonializan", pertenecen a todos los humanos y están a disposición de todos [...] Esta situación inédita provoca un estilo de vivencia y de pertenencia religiosa enteramente distinto al que ha sido común durante los cinco mil años vividos por las religiones. (Vigil, 2012, pp. 39-40).

El horizonte pluralista descrito por Vigil implicaría, en teoría, la no existencia de un predominio de una fe religiosa y la convivencia de múltiples creencias en la sociedad (Guzmán y Arias, 2012). En esta perspectiva, la TPR sería más consciente de que existen muchos caminos válidos en materia religiosa, y estaría en la obligación de aceptar la diversidad y el dinamismo de las creencias (Torradeflot, 1998). El pluralismo religioso de la TPR cristiana no se constituye como un proceso dado y espontáneo; implica, más bien, el surgimiento de distintos enfoques desarrollados mediante una transformación histórica que no es sucesiva. En la actualidad, las principales perspectivas en la TPR son: el eclesiocentrismo (modelo exclusivista), el cristocentrismo (modelo inclusivista) y el teocentrismo (modelo pluralista). ${ }^{10}$

El eclesiocentrismo ${ }^{11}$ niega la posibilidad de salvación a quienes no profesan el catolicismo con el argumento de que solo se lograría mediante la fe exclusiva en Jesucristo y la Iglesia (Garay, 2002), es decir, bajo el precepto de que "fuera de la Iglesia no hay salvación"

culpa por los abusos cometidos en las misiones y a los intereses económicos y políticos del colonialismo, que ha denigrado las religiones del llamado Tercer Mundo" (s. p.).

10 Claude Geffré (2001, s. p.) señala que, frente al reto planteado por el pluralismo de religiones, el cristianismo ha intentado superar el "exclusivismo cristológico" y el "inclusivismo estrecho" mediante el pluralismo o un "teocentrismo radical".

11 Estas tres posturas tienen lugar no solo en el seno católico, sino que se manifiestan en diversas teologías cristianas. (s. p.). El cristocentrismo, sobre todo después del Concilio Vaticano II de 1959, comienza a emerger en el escenario de la discusión teológica. Entre sus premisas está la afirmación de la unicidad y universalidad del Misterio de la salvación en Jesucristo, sin negar la existencia de elementos salvíficos en las otras religiones; en esto último estaría la diferencia con el modelo exclusivista del eclesiocentrismo. Sin embargo, las otras religiones son interpretadas bajo el misterio de salvación en Jesucristo (Garay, 2002), lo que a la larga mantendría el predominio cristiano frente a otras religiones. El cristocentrismo, enmarcado en el modelo inclusivista, no representaría los anhelos pluralistas, pues sería "una forma suavizada de exclusivismo, aparentemente superadora del mismo, pero que de hecho le permite sobrevivir agazapado en zonas más profundas" (Vigil, 2012, p. 31). Para Vigil (2012), el cristianismo ha vivido alrededor de 19 siglos y medio en el modelo exclusivista, y unos 50 años en el inclusivista.

Sin constituirse en una tendencia imponente frente al dualismo exclusivismo/inclusivismo, ya que en la actualidad el sector representativo de la Iglesia católica está "oficialmente en él" (Vigil, 2012, p. 31), surge el "teocentrismo" que, "semejante al cambio de paradigma copernicano en astronomía o del cartesiano en la filosofía" (Garay, 2002, s. p.), pretendería ser más consecuente con el reto pluralista. Propone que el cristianismo estaría en la necesidad de abandonar su sueño de universalidad con respecto a la salvación en Cristo, situando a Dios, "y solo a él" (Garay, 2002 , s. p.), en el centro, ya que cada creencia funda una idea de este, que no es otra cosa que una imagen de lo divino. Las diversas religiones tendrían así el "mismo estatus salvífico" (s. p.), pues prometen un camino válido, "aunque parcial", de salvación (s. p.).

El ideal pluralista impone un desafío enorme para el cristianismo y las demás creencias. Que las doctrinas renuncien a la pretensión de universalidad las conduce a enfrentar algunas dificultades, si se considera el hecho de que para ellas pareciera reinar un principio en el cual no podrían desistir de la exigencia de ser absolutas y universales sin traicionarse a sí mismas (Gómez, 2008). Por ejemplo, Dupuis (2000) subraya su acuerdo con el pluralismo y el "diálogo entre las fes" (p. 571), sin despojarse de los anhelos dominantes. Invoca una "mística de unificación" (p. 571) entre las tradiciones del cristianismo y las de Oriente que se aproxime a una "convergencia escatológica" (p. 571); esta coincidencia no oscurecería el acontecimiento histórico de Cristo, pues él sería el "fin", el "principio" y el "eje central" (pp. 571-572). Esto es lo que Garay (2003) advierte, refiriéndose a 
Knitter, cuando indica que es improbable concebir aseveraciones sobre Cristo sin una comprensión absolutista y definitiva de él. ${ }^{12}$

El diálogo interreligioso se presenta como respuesta posible a las dificultades impuestas por la variedad de creencias que tiene lugar en el pluralismo (Gómez, 2008) sin constituirse en un modelo único y acabado. Desde la posición oficial del catolicismo, en un discurso de 1986, Juan Pablo II $^{13}$ establecía las bases teológicas del diálogo interreligioso en el "misterio de unidad" (Dupuis, 2000, p. 530), un criterio sustantivo de los cristianos. Tal "unidad universal" (p. 530) tendría fundamento en tres principios: el nacimiento y designio compartidos que "toda la humanidad" (p. 530) encuentra en la creación; la unidad del misterio de la redención en Cristo y la expresión del "Espíritu de Dios" (p. 530) en las oraciones de los feligreses de otras comunidades religiosas. En la carta encíclica de 1990 Redemptoris missio, el sumo pontífice añadía que, en algunas circunstancias, el diálogo interreligioso podría erigirse en la "única manera" de ofrecer un verdadero testimonio de Jesucristo, debido a su carácter constitutivo de la misión evangelizadora de la Iglesia. Además, fijaba la imposibilidad de prescindir del Anuncio con el "falso pretexto del proselitismo" (Dupuis, 2000, p. 535), ya que la humanidad tendría el derecho a enterarse de la Buena Nueva. También, dentro de la oficialidad católica, Vigil disentía de la Dominus Iesus, declaración publicada en el año 2000, pues se proponía que el diálogo interreligioso no debería oponerse a un verdadero encuentro "entre iguales"; sin embargo, en lo concerniente al contenido de verdad de las partes que comparecen en el diálogo, este "entre iguales" no podría realizarse, en la medida que la verdad estaría "enteramente del lado del cristianismo" (Vigil, 2012, p. 35).

Sin representar la postura oficial del catolicismo, Jacques Dupuis y José María Vigil exponen una visión del diálogo interreligioso. Dupuis (2000) parece concebir que el reino de Dios es más extenso que la Iglesia, y sería edificado por cristianos y miembros de otras religiones. El diálogo entrañaría el aprendizaje de "verdades nuevas" (Dupuis, 2000, p. 547), erigiéndose en una manifestación genuina del cometido evangelizador. Sin concluir allí, desde esta perspectiva, en el diálogo habría lugar para "invitar a otros a convertirse en discípulos de Jesús" (p. 547). Podría

12 Estos ejemplos son tan solo para ilustrar los problemas que enfrentaría la religión en un escenario pluralista; no se pretende simplificar la situación ni señalar que se trata de una única respuesta.

13 "Discurso del papa a los miembros de la Curia romana el 22 de diciembre de 1986" (Dupuis, 2000, p. 530). entenderse la postura de Dupuis frente al diálogo interreligioso a partir de una referencia al teólogo belga Edward Schillebeeckx: la "unidad, la identidad y la unicidad" (p. 567) del credo cristiano frente a las demás creencias se afirmaría en que se trata de una doctrina que establece su vínculo con Dios a través de Cristo, por medio de una construcción histórica, singular y limitada; en ello radicaría su unicidad e identidad, así como su forzosa restricción histórica. Pareciera revelar que el Dios cristiano podría constituirse, antes que en un distintivo de clausura, en un "símbolo de apertura" (p. 567), y expresa que esta creencia sostendría una conexión provechosa con otras fes. Este beneficioso vínculo, sin embargo, no debería conducir al cuestionamiento de la "unicidad de la religión cristiana" (p. 567), garantizando así el recibimiento de lo positivo de las otras tradiciones sin traicionarse como dogma (Dupuis, 2000).

Por su parte, Vigil (2012) indica que el diálogo interreligioso se diferenciaría de la TPR. Si bien esta podría contribuir al diálogo, en lo fundamental, la cuestión "no es para dialogar con nadie, sino para dialogar con nosotros mismos" (p. 32). No se trataría de un diálogo "interreligioso", sino de uno "intrarreligioso". Vigil advierte sobre la necesidad de renovar la teología cristiana y reinterpretar desde los supuestos del pluralismo buena parte de los distintivos de la liturgia, ya que estos fueron instituidos en otro tiempo por conjeturas inclusivistas que hoy parecerían inadmisibles desde el punto de vista pluralista (Vigil, 2012). Con respecto al diálogo del cristianismo con otras religiones, este teólogo español sugiere "desentronizarse" -renunciar al sitial material, social y simbólico que erigió para sí misma la Iglesia-; adoptar el "teocentrismo" (p. 36) -la creencia cristiana no se constituye en el centro, sino que este se encuentra ocupado solo por Dios-y la idea de que el cristianismo no se aprecie como la religión única, sino como una doctrina más. Debería reconciliarse con las otras creencias de acuerdo con la "pluriformidad de la gracia de Dios" (p. 36), que ha causado la pluralidad religiosa.

En las posiciones descritas se reconoce el pluralismo de religiones como un acontecimiento significativo. No obstante, los criterios fijados para hacer efectivo el diálogo entre doctrinas continúan estableciéndose sobre principios -Dios, la creación, Espíritu de Dios, reino de Dios- que a priori excluirían a algunas de las creencias participantes.

Se han sugerido distintas posibilidades que permitan un diálogo interreligioso. El argumento "metafísico" es una afirmación originada desde el interior de los presupuestos religiosos que proyecta la "Realidad Última” -Dios, Buda, Alá, etc.- como criterio 
común y necesario para el diálogo (Gómez, 2008). Habría así una suerte de unificación de las doctrinas en un consenso universal que desconocería el aspecto del diálogo relacionado con la coordinación de los diversos puntos de vista de los participantes, pues el diálogo interreligioso no sería un ejercicio para unificar creencias (Gómez, 2008).

Como alternativa al principio "metafísico" estaría la premisa "naturalista". Externa a la creencia, indica que los enunciados de las religiones tendrían cierta equivalencia, en tanto son proyecciones humanas y no pueden comprobarse en términos empíricos. Debido a esta imposibilidad no habría forma de pensarlas como explicaciones verdaderas. Como la racionalidad científica y los análisis seculares estarían en la capacidad de ofrecer una visión del mundo comprobable de manera empírica, podrían ser considerados como esos criterios que regularían el diálogo interreligioso (Gómez, 2008). Sin embargo, para los críticos, considerar lo religioso como el resultado de una proyección humana generaría la "alienación de las tradiciones religiosas" (p. 42) y una situación de desconfianza, ya que ninguna tradición religiosa desearía participar en un diálogo en el cual se le señale su falencia cognitiva y su carácter ilusorio.

Como una respuesta a los argumentos "metafísico" y "naturalista", Gómez (2008) propone una salida que, sin llegar a ser definitiva, contemple la necesidad de que el diálogo interreligioso se asiente sobre unos principios heterogéneos: la "Prudencia Epistemológica", que implicaría el reconocimiento de la finitud de las tradiciones religiosas con respecto a la infinitud de la verdad, lo cual posibilitaría la consideración de la propia visión y favorecería la idea de que las otras creencias también poseen una mirada significativa que debe ser contemplada (Gómez, 2008); el "Respeto", que garantizaría la participación en igualdad de condiciones de las tradiciones desde sus propios credos sin que se excluya ninguna; la "Solidaridad", por último, enfatizaría en la mediación operada por un "juicio práctico" que oriente el diálogo hacia la más plena realización del "proyecto de humanidad de los otros" (p. 94) tal y como es comprendido por cada tradición particular.

\section{Legislación y enseñanza religiosa}

\section{Pluralismo y normatividad}

Si se aceptan los presupuestos de que el actual orden político colombiano descansa sobre la teoría del liberalismo político y que la noción de pluralismo es una idea fundamental de esta doctrina, es posible afirmar que la reglamentación surgida tras la firma de la Constitución de 1991 dispuso una serie de normatividades orientadas a crear un Estado pluralista y no confesional en materia religiosa, sin que ello implique un compromiso con el laicismo. ${ }^{14}$ Tal orientación pluralista, que pareciera no se obliga íntegramente con el laicismo, se manifiesta en el Preámbulo de la Constitución de 1991 cuando la Asamblea Nacional Constituyente invoca "la protección de Dios" con el ánimo de sancionar y promulgar la Carta Magna.

En el marco legal colombiano no son pocas las reglamentaciones que respaldan la perspectiva pluralista. Entre las más importantes está la Constitución de 1991 (art. 19), que garantiza el derecho de los ciudadanos a profesar su religión en libertad y a difundirla de modo individual y colectivo. El Pacto Internacional de Derechos Civiles y Económicos (punto 1), el Pacto Internacional de Derechos Económicos, Sociales y Culturales (artículos 2 y 13) y la Convención Americana sobre Derechos Humanos -Pacto de San José- (art. 12) también reconocen la libertad que los ciudadanos poseen para manifestar su religión o sus creencias, tanto en público como en privado, mediante el culto, la celebración de los ritos, las prácticas y la enseñanza. Por su parte, normas como la Ley 133 Estatutaria de Libertad Religiosa y de Cultos de 1994 ratifican las garantías consignadas en la Constitución Política y los tratados internacionales suscritos por Colombia (art. 1) y detallan el ámbito de aplicación de los derechos propios de la libertad religiosa (art. 6). Asimismo, el Decreto 354 de 1998 confirma las prerrogativas que tienen los cultos religiosos, en este caso los no católicos, ante el Estado colombiano.

La aplicación de esta legislación benévola con el pluralismo religioso tiene incidencia en el ámbito educativo. La Ley General de Educación de 1994 otorga a la religión el rótulo de área fundamental y establece su enseñanza como obligatoria (art. 23), amén de insistir en los derechos religiosos consignados en la Constitución y demás normatividades mencionadas (art. 24). El Decreto 4500 de 2006 hace lo propio en su artículo segundo y puntualiza sobre los aspectos característicos de la enseñanza religiosa en el proceso educativo -desarrollo, contenidos, intensidad horaria, evaluación, docentes, planta de personal, deberes de los padres de familia-, y de nuevo alude al derecho que tienen los ciudadanos a la

14 La "relación entre la laicidad y el liberalismo no es obvia ni necesaria” (Rivera, s. f., p. 1); un "Estado liberal protege el pluralismo religioso y la tolerancia, mientras que un Estado laico no es neutral en cuestiones morales y religiosas: este último toma en sus manos la secularización de las instituciones del Estado excluyendo todo contenido religioso de las mismas" (p. 1). 
libertad religiosa (art. 5). Por su parte, el Decreto 354 de 1998 reafirma el derecho a la libertad religiosa consignada en las otras reglamentaciones (art. 10), detalla las concesiones a los credos religiosos - no católicos - en materia educativa: planes y textos educativos (art. 12) y regula lo concerniente a los docentes que deben enseñar la educación religiosa cristiana no católica (art. 13).

En esta sucinta descripción se observa que el conjunto de legislaciones, tanto las de carácter general como las que se refieren de forma específica a la educación, surgidas después de la promulgación de la Constitución Política de 1991, recogen y confirman las garantías de un pluralismo religioso y de un Estado no confesional.

\section{La educación religiosa en la escuela}

El contexto legislativo no es el único, y en el escenario de diversidad de creencias y pluralismo tiene lugar la denominada Enseñanza Religiosa Escolar (ERE). Esta se concibe como una de las nueve áreas fundamentales y básicas, según lo estipula la Ley 115 -art. 23 y $24-$, encargada de las preocupaciones "eminentemente humanas" que "afectan al ser" y al "sentido último de la vida", dada su "fuerte incidencia en el núcleo sustancial de las personas" (Coy, 2010, p. 78). Es decir, que, según esta perspectiva, "para que haya verdadero desarrollo integral humano" (p. 74) la dimensión espiritual y religiosa tendría que considerarse como fundamental dentro del currículo. Las esferas religiosa y espiritual serían aquellas "manifestaciones, actitudes, costumbres, creencias y ritos" (p. 74) relacionadas con el discernimiento sobre el bien y el mal, así como con el "sentido último" y "más profundo de la vida" de las personas y sociedades que a través de los interrogantes de los seres humanos "ha sido y continúa siendo evidente" (p. 74).

De acuerdo con esta concepción, la ERE tiene que ocuparse de ciertos espacios que constituyen la religión y la vinculan con otras áreas de enseñanza. Estos ámbitos son las dimensiones "cultural", "éticomoral", "teológica", "cognitiva” y "antropológica" de la religión (García, 2014). La dimensión "cultural” tiene que ver con la "forma de la religión" (p. 18) en sí, esto es, con el carácter específico que adquiere; la "éticomoral" está vinculada a la comprensión del deber y la "praxis social" de la creencia; la "teológica" posibilitaría el entendimiento de los soportes epistemológicos que apoyan la "confrontación, el diálogo y la reflexión crítica" (p. 18) de la doctrina con las otras ciencias del conocimiento; la "cognitiva" propiciaría el desarrollo de pensamiento, y la "antropológica", se constituiría en aquella que propone un modelo de persona.
Desde esta perspectiva, el lugar de la ERE en la escuela se justificaría gracias a la exploración que realiza del "horizonte trascendente del ser humano" (p. 19). Este planteamiento sugiere que la educación que no contemple la esfera religiosa, espiritual o trascendente es incompleta, ya que no estimaría un espacio que hace parte del ser humano y que posibilita en los estudiantes el análisis de los "interrogantes de sentido" del "ser de la persona en el mundo" (p. 21). Para este grupo de propuestas, el ámbito religioso se establece como una "dimensión constitutiva del ser humano" (Muñoz, 2014, p. 251) y de la cultura.

La justificación del ámbito religioso en la enseñanza escolar tendría, entonces, un sólido fundamento en el hecho de que si se examina al hombre de las "sociedades tradicionales", se trataría de "un homo religiosus" (Eliade, 1967, p. 22), por lo que estudiar la esfera religiosa que ha hecho presencia en el curso de la humanidad se constituiría en un aspecto fundamental de la ERE.

La ERE tendría los siguientes objetivos pedagógicos: 1) capacitar a los estudiantes para el diálogo interreligioso; 2) apoyar la construcción de un juicio que permita analizar cómo las creencias se desarrollaron sobre principios culturales específicos; 3 ) ampliar las facultades que les posibiliten "cultivar" y "crecer" en su identidad religiosa (García, 2014, p. 36); 4) favorecer la "maduración humana" (Muñoz, 2014, p. 258) a partir de la orientación de los valores morales y religiosos hacia una experiencia de lo trascendente (Coy, 2010, p. 63), ya que los alumnos están interrogándose por el "sentido último" (López, 2014, p. 53) de la vida y las implicaciones religiosas y éticas que ello involucra: la historia, el mundo, los fracasos, la muerte. 5) Ayudar a la búsqueda del desarrollo humano integral, en la medida en que se ha demostrado, por parte de "la historia, la sociología, la psicología, la arqueología o la paleografía" (Coy, 2010, p. 66), que la religión históricamente se ha constituido en un fundamento para alcanzarlo y que el hecho religioso es un fenómeno que no se puede ignorar en ninguna de las civilizaciones actuales y precedentes (Coy, 2010).

En general, estas perspectivas sitúan a la ERE como un área escolar que respaldaría la construcción de un saber acerca de lo religioso, donde el educando explore y alcance los "significados últimos y globales de la realidad y de la experiencia humana" (Coy, 2010, p. 79), así como los "valores esenciales" (p. 79) para su existencia, lo cual le permite determinar "hitos" y "perspectivas reales" que respondan a los propósitos de la ERE y ofrezcan "alternativas de vida" y de "participación” (López, 2014). 


\section{Educación religiosa pública y no confesional}

\section{Escuela pública y enseñanza religiosa confesional}

Pese al progreso moderado de la normatividad y a la consideración de perspectivas pluralistas en el seno del dogma católico, las prácticas educativas en la esfera de lo público no parecen corresponder con estos avances. Ello muestra que la ley en sí misma no transforma. Con frecuencia se encuentra en las escuelas públicas que hay un privilegio del catolicismo, muy cercano, en algunos casos, al catecismo propio de una educación y un Estado confesionales.

Es probable que favorecer un credo sobre otros en la escuela pública sea incompatible con la actitud que debería esperarse de una sociedad que se inscribe a un Estado pluralista. De tal manera, se presumiría que los integrantes de la sociedad encargados de la enseñanza religiosa pública deberían ser coherentes con esa condición del pluralismo, es decir, con el hecho de que ninguna religión puede pretender ofrecer el punto de vista total y absoluto, la comprensión definitiva y más verdadera de la realidad o el camino exclusivo de la salvación o liberación humanas (Gómez, 2014). El pluralismo en lo religioso se materializaría en el principio de que

\section{[...] es tan legítimo y racional para los adeptos de una religión particular creer en sus preceptos y vivir de acuerdo con ellos, como lo es para los seguidores de cualquier otro credo aceptar los preceptos de su doctrina. Esto es, que no puede afirmarse que sea más racional creer en una determinada doctrina religiosa que en otra. (Gómez, 2008, p. 46).}

Esta forma de entender el pluralismo religioso exigiría en la práctica educativa de las escuelas públicas la necesidad de reconocer "que los otros tienen igual derecho a creer y propagar sus creencias, sin sentirse atacados o violentados" (Mendoza y Velandia, 2013, p. 111). Si la actitud estatal concuerda con este atributo del pluralismo, a los encargados de la enseñanza les correspondería expresar una posición de imparcialidad referente al hecho de que no tendrían que amonestar, excluir o asumir como propias las aseveraciones formuladas por ninguna creencia particular. En ese sentido, la educación pública que se oriente hacia una ERE confesional no solo estaría contradiciendo ese distintivo de imparcialidad propio de toda institución pública en un Estado que legisla a favor del pluralismo, sino que se opondría a su propio marco legislativo y a los tratados suscritos en esta materia:
1. Objetaría la Constitución Política de 1991: los artículos 1, que establece que "Colombia es un Estado [...] pluralista"; 18 y 19 que garantizan la libertad de cultos, de conciencia y pensamiento, así como el precepto constitucional de que "Todas las confesiones religiosas e iglesias son igualmente libres ante la ley" (Constitución Política de Colombia, 1991).

2. Negaría la Ley 133 Estatutaria de Libertad Religiosa y de Cultos de 1994, que en su artículo 2 señala que "Ninguna Iglesia o Confesión religiosa es ni será oficial o estatal" (Ley 133, 1994).

3. En el ámbito educativo negaría el artículo 6 del Decreto 4500 de 2006 que establece que "Ningún docente estatal podrá usar su cátedra, de manera sistemática u ocasional, para hacer proselitismo religioso o para impartir una educación religiosa en beneficio de un credo específico" (Decreto 4500, 2006).

4. En la esfera de los convenios pactados contrariaría la Convención Americana sobre derechos Humanos - Pacto de San José- que en su artículo 12 proclama la "Libertad de Conciencia y de Religión" (Convención Americana sobre Derechos Humanos, 1969).

Privilegiar un credo en la escuela pública también es incompatible en la propuesta misma de una ERE pluralista. El presupuesto fundamental de una ERE coherente con el pluralismo religioso "no radicaría en adoctrinar o catequizar" en una "tradición de fe particular" (García, 2014, p. 34), sino en propiciar espacios reflexivos, por medio de la concientización y el desarrollo de contenidos, a partir de los cuales sea posible analizar una realidad plural en materia religiosa. La ERE confesional, en este sentido, no estaría acogiendo el pluralismo religioso como fundamento epistemológico (García, 2014; Pardo, 2014). En el caso de la escuela pública, esta, por un lado, no avanzaría hacia una comprensión de los fundamentos de otras religiones, acercándose al anhelo de universalidad que pretende privilegiar una fe sobre otra (Guzmán y Arias, 2012); por el otro, se alejaría de la máxima de justicia que favorece a las doctrinas religiosas en la enseñanza pública y pluralista.

\section{Libros de texto confesionales}

En la ERE pública se observa el privilegio concedido por algunos manuales de enseñanza a la fe católica. El favorecimiento tiene lugar en textos editados después de 1991, fecha en la que se iniciaría de manera formal la legislación pluralista en el país, tras la promulgación 
de la nueva Constitución Política. Los textos consultados para esta investigación, escogidos porque circulan en instituciones públicas de Bogotá, ${ }^{15}$ se sustentan en la Guía para el desarrollo de los contenidos de la enseñanza religiosa escolar en los niveles de básica secundaria y media (Conferencia Episcopal de Colombia, 1994). Este documento advierte que su enfoque pedagógico "extiende el respeto de la libertad religiosa [...] a los alumnos que toman las clases" (p. 10), en concordancia con el ámbito legal propiciado por la Constitución. Sin embargo, señala que el análisis religioso "no se puede hacer en abstracto" y para que los estudiantes "sepan lo que es la religión" es necesario hacerlo desde una "experiencia religiosa concreta" (p. 13). Se trata, pues, de enseñar el "hecho católico" como esa práctica que se justifica en la escuela porque es la "más presente cultural e históricamente en el contexto de los alumnos" y "un número mayoritario de conciudadanos la profesan" (p. 13). Asimismo, el "argumento jurídico fundamenta el estudio de la religión católica en la escuela colombiana" (p. 13) de la mano del acontecimiento de que el "pueblo colombiano ha sido educado en la fe católica" (p. 15).

La Guía establece que el "objeto de estudio" de la ERE "es la Revelación cristiana y su experiencia religiosa" (p. 18), donde no solo se aprendan los "aspectos doctrinales del credo católico" (p. 18), sino sus manifestaciones en la cultura, la historia y la sociedad. Desde esta perspectiva, la ERE asume, entonces, como objetivos pedagógicos el "transmitir y enseñar" la misión de la Iglesia y la "fe recibida por revelación divina" (p. 19).

De acuerdo con estas orientaciones se selecciona Jardín Católico: educación religiosa (Tobón y Montoya, 2004); un texto que evidencia que desde los grados iniciales se favorece una creencia en la ERE pública. Dirigido a la "Educación Religiosa para Preescolar", traza como "objetivo primordial" el "acercamiento al proyecto de vida propuesto por Jesús" (p. 4) que le posibilite al niño "iniciar una vida verdaderamente cristiana" a partir de los principios de la "fe cristiana" (p. 4), así como suscitar "admiración ante las maravillas de la creación” y "agradecimiento hacia el Padre

15 Se presentará una breve descripción. Los criterios que orientaron la selección fueron los siguientes: 1) material confesional publicado después de la legislación pluralista; 2) que en la actualidad son utilizados por maestros de colegios públicos de Bogotá para impartir la ERE, y 3) que corresponden a cada uno de los niveles en los que está organizado el sistema educativo formal en Colombia (preescolar, básica primaria, básica secundaria y media). Es necesario aclarar que en la actualidad existen libros de texto que presentan un enfoque pluralista, sin embargo, aún no circulan por las instituciones públicas en las que se realizó la búsqueda.
Dios" (p. 4). Presenta cuatro unidades, divididas en varios temas, en las que se señalan un "Logro" y unas "Indicaciones" para los maestros.

La unidad uno, "Dios creador y padre", muestra que el logro debe estar orientado a que, al niño, por medio de las más simples experiencias, le sea posible el "encuentro y la relación con Dios Padre" (p. 5). Las "Indicaciones", por ejemplo, en el tema 5, "Dios me dio una Madre en el cielo", proponen al docente que puede iniciar con una explicación sencilla sobre la "historia de la Virgen María y la importancia que tiene" (p. 18) y enseñar una "oración [sobre la Virgen] a sus alumnos y alumnas" (p. 19). La unidad dos, titulada “¡Gracias, Señor!”, fija como "Logro” el que los estudiantes tomen "conciencia de la necesidad de dar gracias al Señor en todo momento por el gran regalo de la creación" (Tobón y Montoya, 2004, p. 20). En las "Indicaciones" se le sugiere al maestro que invite a los niños a que agradezcan al Señor por todos los bienes de la naturaleza (Tobón y Montoya, 2004).

"Dios se hizo hombre" es como se denomina la tercera unidad, cuyo "Logro" es "Descubrir a Jesús como 'la gran noticia para la humanidad', que nos muestra cómo es Dios Padre" (p. 29). Algunas de las "Indicaciones" se refieren a la "narración sencilla de la historia del nacimiento de Jesús" (p. 30) y a que el docente "recitará con sus alumnos y alumnas la oración del Padre nuestro" (p. 37). Este manual finaliza con la unidad cuatro, titulada "La comunidad cristiana"; allí se especifica como "Logro" la importancia de "Favorecer el descubrimiento de la Iglesia que, animada por el Espíritu Santo, proclama su fe, la celebra, la comparte y la vive" (p. 43). En las "Indicaciones" de uno de los temas de esta unidad, "Los amigos de Jesús formamos la Iglesia", se le propone al maestro la posibilidad de concluir la temática "con algún canto o ronda relacionado con la Iglesia o el Bautismo" (p. 49).

Otro prototipo es el libro Proyecto de vida 5: valor del testimonio (Tobón y Montoya, 2002), dirigido a la ERE de básica primaria, cuyas lecciones también revelan el favorecimiento de la doctrina católica y la suscripción a las orientaciones de la Conferencia Episcopal Colombiana. Despliega una estructura pedagógica organizada en 19 temáticas, cada una con una serie de componentes llamados en el texto como "Logro básico", "Actividad", "Experiencia”, "Mensaje”, "Aprendo" y "Compromiso". Por ejemplo, el "Tema 19", "María inmaculada anima y fortalece la esperanza cristiana", tiene como "Logro básico" "Reconocer en María Inmaculada a la Buena Madre que permanentemente anima y fortalece a la Iglesia en su esperanza de la 
Patria definitiva" (Tobón y Montoya, 2002, p. 107) y como "Experiencia" el hecho de que "Nuestra madre nos ama" (p. 107).

En la "Actividad 4" se invita a los niños a que en grupos y con cartulinas se dibuje a la Madre de Dios y se le escriba un mensaje que "exprese que ella es nuestra madre y la madre de la Iglesia" (p. 110); allí el componente "Aprendo" enseña que "María en todo momento estuvo integrada al proyecto de salvación que Jesús vino a traer al mundo", y que "es nuestra madre y la madre de la Iglesia y nos acompaña en nuestro caminar hacia la patria del Padre" (p. 110). Por último, se indica que de "manera alternada, recemos a María la oración de la Salve" (p. 111) y se determina como "Compromiso", que el estudiante debe apuntar en el cuaderno la obligación de "permanecer unido a María puesto que ella siempre está dispuesta a acompañarme en mi lento caminar hacia el Padre Dios" (p. 111).

En la básica secundaria uno de los textos utilizados es Compromiso Moral. Educación religiosa, grado noveno (Comunidad Hermanas Vicentinas, 2005a), el cual se circunscribe a las orientaciones y a la aprobación de la Conferencia Episcopal de Colombia. Organizado para realzar la fe católica, presenta cuatro unidades, cada una con un "Objetivo General", "Objetivos Específicos", "Sugerencias de actividades”, "Propuestas de Logros" y "Propuestas de indicadores".

Como ejemplo, se describirán algunos de estos componentes con base en la segunda unidad "Fundamento trinitario de la moral cristiana". El "Objetivo General" propone la identificación del "fundamento trinitario de la moral cristiana" (Comunidad Hermanas Vicentinas, 2005a, p. 29) e indica que dentro de los "Objetivos Específicos" el alumno debe estar en la capacidad de "descubrir que la moral cristiana es comunión con Dios" y reconocer que la "moral cristiana tiene como fundamento a Cristo y su Evangelio" (p. 29). La "Propuesta de Logros" evalúa si el alumno "vive según el espíritu de Jesús", mientras que la "Propuesta de Indicadores" observa si el estudiante "manifiesta interés por seguir el camino de Jesús" (p. 29). Por su parte, la última unidad, denominada "El compromiso moral del cristiano hoy", revela como "Objetivo General" el conocimiento de los "aspectos prioritarios del compromiso moral del cristiano para vivir coherentemente" (p. 65). La "Propuesta de Indicadores" estima si el estudiante "confronta las vivencias del hombre de hoy con lo propuesto en la moral cristiana" y si "valora la propuesta del Reino hecho por Jesús" (p. 65).
En otro libro de texto, Protagonista de una Nueva Sociedad. Educación religiosa 11 (Comunidad Hermanas Vicentinas, 2005b), se muestran tres unidades nombradas de acuerdo con el documento episcopal, con una estructura dividida en "Objetivos", "Sugerencias de Actividades", "Propuesta de Logros" y "Propuesta de Indicadores". A modo de ejemplo, solo se tratará la primera. Se titula "La Realidad Social a la luz de la Doctrina Social de la Iglesia", ${ }^{16}$ en su "Objetivo General" postula la importancia de desarrollar en los estudiantes la capacidad de pensar la realidad nacional y mundial desde una interpretación "en clave de liberación cristiana" (Comunidad Hermanas Vicentinas, 2005b, p. 5), mientras que los "Objetivos Específicos" proponen la identificación de los "elementos fundamentales en el análisis cristiano" (p. 5) y la descripción de la "visión de esperanza" que el "cristiano da" (p. 5) sobre la realidad. La "Propuesta de Logros" y la "Propuesta de Indicadores", por lo tanto, se corresponden con los propósitos pedagógicos de los "Objetivos" y evalúan si el estudiante "Identifica los aspectos y la metodología en el análisis cristiano de la realidad" (p. 5) y "Aplica la metodología de la Doctrina Social de la Iglesia en el análisis de un problema" (p. 5).

En esta breve descripción se observa el privilegio concedido por algunos manuales de enseñanza a la fe católica, que se fundamentan en la Guía para el desarrollo de los contenidos de la enseñanza religiosa escolar en los niveles de básica secundaria y media (Conferencia Episcopal de Colombia, 1994) y están dirigidos a cada uno de los niveles del sistema educativo formal en Colombia: preescolar, básica primaria, básica secundaria y media. No puede asegurarse que de acuerdo con los contenidos de unos ejemplares el fenómeno se presente en el conjunto de la escuela pública; sin embargo, es posible situarlos como un indicador de cómo la ERE confesional hace presencia en centros educativos públicos. La dificultad no radica en que estos textos de enseñanza privilegien el catolicismo como doctrina para la ERE, sino que sean utilizados en la escuela pública por maestros de colegios oficiales. Esto sería problemático con el pluralismo religioso, en la medida en que en la esfera pública no sería justo con las diversas doctrinas la preferencia de una, pues en la educación de un Estado que legisle a favor del pluralismo las creencias poseerían igual derecho a propagar su fe.

16 En el documento episcopal esta se titula "La realidad a la luz de la Doctrina Social de la Iglesia" (Conferencia Episcopal de Colombia, 1994, p. 161). 


\section{Una propuesta de educación religiosa para la escuela pública}

Se ha señalado que una ERE confesional en la educación pública es incompatible con 1) la actitud de un Estado que legisla a favor del pluralismo y 2) el carácter de una ERE pluralista. Como propuesta para una ERE coherente con el sentido de la escuela pública y el pluralismo, que no evidencie las incompatibilidades con 1) y 2), se sugiere una ERE que despliegue como principios insoslayables a) el no favorecimiento de ninguna creencia y b) el abandono del adoctrinamiento religioso. ${ }^{17}$ Para que un proyecto de ERE no refleje los conflictos con 1) y 2) y sea congruente con a) y b) es necesario que estudie el fenómeno religioso desde una iniciativa que se denominará ERE desde un enfoque no confesional. ${ }^{18}$

Esta propuesta se traza como objetivos una ERE que respalde la construcción de un saber acerca de lo religioso a partir de un conjunto de conocimientos, que contribuya en los estudiantes a una reflexión sobre las diversas creencias desde una perspectiva coherente con el pluralismo y evite la preferencia y el adoctrinamiento religiosos. Se propone un escenario en el cual ellos desarrollen elementos para comprender que la experiencia religiosa es un fenómeno que no se puede ignorar; que las distintas creencias se han dado sobre la base de principios históricos, espaciales y culturales específicos, y no existe algo así como una religión única o verdadera. La idea es que en la escuela pública se transforme esa práctica en la cual una determinada religión ${ }^{19}$ se presenta "como un sistema de creencias revelada" que es "obligatoria" y se debe "imponer a todos" (Corbí, 2007, p. 201), donde se someta "el pensar, el sentir y el comportamiento" (p. 201) de los estudiantes.

En esta iniciativa se sugiere que la religión y sus diversas manifestaciones sean concebidas como construcciones humanas con un modo histórico y finito, que deja comprender los "momentos capitales" (Hegel, 1984, p. 84) y la manera como se han establecido. Es dable observar, entonces, cómo la religión, en sus distintas expresiones, se ha conectado con las representaciones más concretas de lo

17 No es una idea nueva, autores como Diez de Velasco (1999) en España y el Centro de Estudios Teológicos y de las Religiones, CETRE, de la Universidad del Rosario en Colombia proponen un estudio de la religión desde un lugar no confesional.

18 Diez de Velasco (1999) la denomina "Historia de las religiones" y el CETRE la "Perspectiva interdisciplinar".

19 En el caso de la escuela pública en Bogotá, se trata del credo católico, pero la propuesta abarca al conjunto de creencias religiosas. divino: "aquellos a quienes se les ocurrieron tales religiones son hombres; por tanto, ahí debe existir alguna razón" (p. 101). Se propone el reconocimiento de la religión como una forma humana que permite advertir la fuente que la posibilitó en su carácter de creencia, donde las distintas configuraciones que el fenómeno tome facilitan su entendimiento a partir de la "contingencia y el localismo" (p. 101).

Para esta propuesta se sugiere una ERE interdisciplinar que permita integrar las contribuciones de aquellas disciplinas que estudiarían la religión desde una orientación holística y no confesional: filosofía, historia, filología, antropología, sociología, psicología. En general, y dada la complejidad de lo sagrado, es difícil establecer los límites entre las propiedades que corresponde investigar a cada disciplina, y en ocasiones "comparten" las fuentes o fijan su atención sobre los "mismos" atributos del aspecto religioso. Como un sustento a la ERE desde un enfoque no confesional en la escuela pública, se presentan algunas observaciones que habrían de considerarse. La enumeración no pretende ser exhaustiva; ${ }^{20}$ no aborda las tendencias, los enfoques o los debates metodológicos acaecidos en el escenario particular de cada una, ni procura agotar sus posibilidades explicativas. Se trata de una proposición limitada que traza tan solo uno de los caminos que podría seguirse.

La filosofía de la religión ayudaría al entendimiento del fenómeno religioso en la medida en que es una investigación acerca de los "últimos fundamentos" en que lo sagrado se revela (Alessi, 2004). Sin constituirse en una "rama de la teología", indaga lo religioso desde una perspectiva que no delinea como objetivo la "defensa de las convicciones religiosas" (Hick, 1990, p. 1). Su análisis se acerca a "una actividad de segundo orden" (p. 1) que no hace parte de la religión, sino que desde las particularidades de las religiones y teologías se encarga de la comprensión de los fundamentos de la experiencia religiosa y de aquellas acciones relacionadas con la devoción (Hick, 1990). También contribuiría al estudio de los conceptos que caracterizan lo religioso: Dios, sagrado, vida eterna, salvación, sacrificio, devoción, y a la comprensión de la "naturaleza de la religión" (p. 2) y sus posibles vínculos con otras creencias. Es un intento por develar el significado de lo

20 En el estudio de las religiones existen, señala Diez de Velasco (2002):

[...] campos tan fascinantes que pueden ofrecer posibilidades insospechadas como puede ser la biología (en especial la neurofisiología, las ciencias del cerebro y en general la ciencia cognitiva de la religión, que parece el camino para el estudio de la religión más prometedor en los años venideros), pero también la geografía (de las religiones), la ecología (de las religiones), la economía, las ciencias jurídicas, la etología, etc. (p. 22). 
sagrado y por comprender su "estructura fundamental, intrínseca y objetiva" (Alessi, 2004, p. 48), sin que ello implique lo genérico o un "común denominador de todas las religiones" (p. 47).

Asimismo, la filosofía de la religión participaría mediante la "descripción y el examen crítico" de lo religioso y su "contenido proposicional" (Ferrater, 2002, p. 3063). De tal manera que podría ocuparse de asuntos como la relación entre los compendios morales y la creencia; la estructura y las formas adoptadas por los enunciados y la experiencia religiosas; los valores del credo y su posible vínculo con los de otras doctrinas; los modos de "aprehensión del llamado 'objeto' de la creencia religiosa" (Ferrater, 2002, p. 3064); la naturaleza y justificación de los preceptos que la creencia manifiesta para explicar sus postulados.

La historia de la religión colaboraría con el análisis del proceso temporal de las tradiciones religiosas y de las vicisitudes de sus desarrollos como creencias y prácticas, así como con el examen de los eventos que la han afectado, sus costumbres o zonas de influencia, es decir, que describe las "modalidades de lo sagrado y la situación del hombre en un mundo cargado de valores religiosos" (Eliade, 1967, p. 23). Del mismo modo, explicaría las causas que la condujeron a la formación de distintas escuelas y su relación con otras religiones, en tanto sintetiza las complejidades de cada fe para comprenderla con respecto a las demás, situándola como "experiencia, práctica y creencia humana" (Diez de Velasco y García, 2002, p. 13l). Pretende descifrar el curso de lo sagrado por medio de un análisis que advierta que su avance se condiciona por un momento histórico que lo hizo posible (Eliade y Kitagawa, 1967), donde las variables espacio temporales se constituyen como "consustanciales a la percepción del propio acontecimiento" (Bermejo, 2002, p. 260) religioso.

Son centrales las contribuciones de lo que podría denominarse filología de la religión, en tanto las fuentes escritas, en particular los textos sagrados, han sido una de las formas en que lo religioso se ha materializado. Es importante elaborar un razonamiento que contemple las circunstancias históricas, espaciales, sociales, políticas y económicas en las cuales se produjeron los documentos sagrados, que permita comprender su naturaleza como "obras de hombres" y no como "revelaciones divinas intemporales y de valor eterno" (Diez de Velasco, 2002, p. 20). Por su parte, la antropología religiosa, según el enfoque que adopte -evolucionista, funcionalista o simbólico-, asistiría en el análisis al esclarecer el origen y desarrollo de las creencias, las funciones que estas desempeñan en la sociedad y el significado para quienes las practican (Marzal, 2002). El aspecto antropológico de la religión ayudaría a establecer las diversas formas en que los mitos y los rituales religiosos operan en la vida de las personas (Kolakowski, 1988) y a determinar los vínculos existentes entre el acontecimiento religioso, la mente humana y la cultura que lo concibe.

La sociología de la religión explicaría los vínculos entre la creencia y las entidades sociales, las "formas de la institucionalización religiosa" (Berger, 2006, p. 7) y su problematización en la vida social. Por medio de interrogantes articulados con el lugar y el papel de la religión en la sociedad (Mendieta, 2002), el estudio sociológico permitiría entender las "raíces" de lo religioso y su materialización en la "praxis cotidiana" (Berger, 2006, p. 7) del individuo y la sociedad. Esta disciplina contribuiría con elementos de análisis para conocer las condiciones fundamentales de la inteligibilidad de la creencia y de su significación histórica (Weber, 1997). También posibilitaría el conocimiento de aquellos factores que han condicionado el "estilo de vida" (Weber, 1997, p. 6) de los creyentes, así como la probabilidad de comprender la relación entre los "estratos sociales" y la "ética práctica" (p. 6) nacida en cada doctrina; por ejemplo, saber que "el hinduismo surgió en una casta hereditaria de literatos cultos" (p. 6). De una manera general, podría señalarse que una de sus tareas ha sido "explicar, analizar, catalogar y hacer comprensibles las experiencias, prácticas e instituciones de la religión" (Mendieta, 2002, p. 103).

La psicología de la religión facultaría la observación de los "componentes de lo individual en la religión" (Diez de Velasco, 2002, p. 22) y el entendimiento de los comportamientos humanos, personales y colectivos - "experiencias cumbre", "conciencia alterada" (p. 22) - como fenómenos relacionados con distintas manifestaciones de lo sagrado. Esta perspectiva de estudio analiza los posibles vínculos entre la creencia y ciertos problemas asociados a la socialización e individuación (Diez de Velasco, 2002); al examen del elemento psicológico en los comportamientos y actitudes de quienes practican una religión; a la investigación de las "experiencias y vivencias conscientes" (Gómez, 2002, p. 149) de los creyentes, así como su intencionalidad.

\section{Consideraciones finales}

Durante este trabajo se ha señalado cómo en la actualidad el fenómeno religioso, en las variadas y complejas formas que ha adquirido, influencia diversos campos que van desde los comportamientos más 
privados del individuo hasta las acciones más públicas del Estado. Ese influjo religioso, no obstante, tiene que enfrentar un problema asociado al pluralismo, que no es solo un principio insoslayable del liberalismo político, sino que es una actitud que interpela, tanto al espacio mismo de la creencia, como al de la enseñanza religiosa. En tal sentido, se manifestó que en el campo político el "pluralismo razonable", cuya conceptualización se sitúa en la propuesta de Rawls, podría constituirse como fundamento para una sociedad inscrita en el liberalismo político, y que este es razonable gracias a que se establecería en un modo viable para soportar los potenciales excesos de las creencias y los poderes que desequilibran a la sociedad, lo cual propicia un escenario racional y admisible para las mayorías. En ese sentido, se indicó que el Estado colombiano y su cuerpo legal se inscriben en el liberalismo político, y que tras la promulgación de la Constitución Política de 1991 surgió un universo legislativo propio de un Estado no confesional y pluralista.

Se sugirió que el pluralismo se constituye como una actitud factible para la convivencia entre las diversas creencias en el mundo contemporáneo, en tanto permitiría una conducta destinada a no despreciar las otras doctrinas y a sustituir la pretensión de ser la única verdadera. Se observó, así, que en el campo de la educación pública es necesaria una ERE que favorezca el estudio de lo religioso desde una perspectiva que evite el adoctrinamiento y esté acorde con el pluralismo. De modo que los estudiantes comprendan, ante todo, la experiencia religiosa como un fenómeno importante para muchos seres humanos, y las diversas creencias como un producto de unas condiciones históricas, espaciales y culturales específicas, es decir, que han sido construcciones humanas.

En consecuencia, se señalaron unos interrogantes sobre la religión y su enseñanza: ¿Qué sitio le corresponde a la educación religiosa en la escuela pública? En un Estado que legisla a favor del pluralismo ies compatible una enseñanza religiosa pública que privilegie un credo? Se sugirió, al respecto, una ERE desde un enfoque no confesional, dada la incompatibilidad entre el pluralismo y una educación religiosa que en lo público favorezca una creencia.

Esta propuesta aspira a constituirse en una posibilidad coherente con el pluralismo y el sentido no confesional que le corresponde a la escuela pública. $\mathrm{Su}$ objetivo es brindar a los estudiantes una perspectiva sobre las religiones y los aspectos que componen lo religioso a partir de tres criterios: 1 ) las contribuciones analíticas sobre el fenómeno religioso elaboradas por la filosofía, la historia, la filología, la antropología, la sociología y la psicología; 2) la congruencia con los principios insoslayables de a) no favorecer ninguna creencia y b) no utilizar la cátedra para el adoctrinamiento religioso; y 3) la coherencia con a) el proceder de un Estado que legisla a favor del pluralismo y b) los preceptos de justicia que amparan las creencias en una ERE pluralista que se proyecte en el ámbito de lo público. Se trata, entonces, de una ERE que se distancie de algunas prácticas ocurridas en la escuela pública, donde la reflexión sobre lo religioso se reduce a transmitir "el gran mensaje de las viejas y venerables tradiciones" (Corbí, 2007, p. 232), así como sus narraciones sagradas, sus símbolos y sus mitos como los únicos y verdaderos.

La ERE desde un enfoque no confesional aspira a consolidarse en una asignatura escolar que entienda la religión y sus diversas expresiones como construcciones humanas que poseen una forma histórica y finita que puede ser comprendida. Asimismo, como un área que en la escuela pública se distancie de la óptica teológica y estudie las religiones desde una perspectiva 1) "no exclusiva", en cuanto respeta el principio de justicia que asiste a las creencias en el marco del pluralismo (Diez de Velasco, 1999); 2) "diversa", pues propicia en los estudiantes la comprensión de la complejidad del fenómeno religioso y sus múltiples materializaciones, y 3) "no esencialista", donde el alumno entienda las experiencias religiosas como productos de la sociedad, y no en términos de "un mensaje esencial o de una religión original, verdadera o natural" (Diez de Velasco, 1999, p. 89).

\section{Referencias}

Alessi, A. (2004). Los caminos de lo sagrado. Introducción a la filosofía de la religión. Madrid: Cristiandad.

Bastian, J. P. (1997). La mutación religiosa en América Latina. Para una sociología del cambio social en la modernidad periférica. México: Fondo de Cultura Económica.

Berger, P. (2006). El dosel sagrado. Para una teoría sociológica de la religión. Barcelona: Kairós.

Bermejo, J. C. (2002). El método comparativo y el estudio de la religión. En F. Diez de Velasco y F. García (Eds.), El estudio de la religión. Madrid: Trotta.

Bonilla, J. L. (2011). Teología del Pluralismo Religioso: paradigma y frontera. Franciscanum. Revista de las ciencias del espíritu, 53 (156), 75-104.

Comunidad Hermanas Vicentinas. (2005a). Compromiso Moral. Educación religiosa, grado noveno. Bogotá: Kimpres. 
Comunidad Hermanas Vicentinas. (2005b). Protagonista de una Nueva Sociedad. Educación religiosa 11. Bogotá: Kimpres.

Constitución Política de Colombia. (1991). Recuperado el 1 de noviembre de 2016, de http://www.corteconstitucional.gov.co/inicio/Constitucion $\% 20$ politica $\% 20$ de\%20Colombia\%20-\%202015.pdf

Conferencia Episcopal de Colombia. (1994). Guía para el desarrollo de los contenidos de la enseñanza religiosa escolar en los niveles de básica secundaria y media. Bogotá: SPEC.

Convención Americana sobre Derechos Humanos. (1969). Recuperado el 1 de noviembre de 2016, de https:// www.oas.org/dil/esp/tratados_b-32_convencion_americana_sobre_derechos_humanos.htm

Corbí, M. (2007). Hacia una espiritualidad laica: sin creencias, sin religiones, sin dioses. Barcelona: Herder.

Coy, M. E. (2010). La educación religiosa escolar en un contexto plural. Reflexiones preliminares. Franciscanum. Revista de las ciencias del espíritu, 52 (154), 53-83.

Diez de Velasco, F. (1999). Enseñar religiones desde una óptica no confesional: reflexiones sobre (y más allá de) una alternativa a Religión en la escuela. Revista de Ciencias de las Religiones, 4, 83-101. Recuperado el 1 de noviembre de 2016, de https://revistas.ucm.es/index.php/ILUR/article/download/ ILUR9999140083A/26792

Diez de Velasco, F. (2002). Introducción a la historia de las religiones. Recuperado el 28 de agosto de 2017, de https://antroporecursos.files.wordpress. com/2009/03/diez-de-velasco-f-2002-introducciona-la-historia-de-las-religiones.pdf

Dupuis, J. (2000). Hacia una teología cristiana del pluralismo religioso. Santander: Sal Terrae.

Eliade, M. (1967). Lo sagrado y lo profano. Madrid: Guadarrama.

Eliade, M. y Kitagawa, J. (1967). Observaciones metodológicas sobre el estudio del simbolismo religioso. En M. Eliade y J. Kitagawa (Comp.), Metodología de la historia de las religiones (pp. 116-139). Buenos Aires: Paidós.

Ferraro, B. (2005). El desafío de la fe en un mundo plural. Dominus Iesus: problemas pendientes y puertas abiertas. En J. M. Vigil (Coord.), El actual debate de la Teología del Pluralismo después de la Dominus Iesus (pp. 31-37). Recuperado el 17 de septiembre de 2016, de http://www.servicioskoinonia.org/LibrosDigitales/ LDK/LDK1.pdf
Ferrater, J. (2002). Diccionario de Filosofía. Tomo IV. Barcelona: Ariel.

Garay, J. (2002). Teología del pluralismo religioso y teología de la liberación. Recuperado el 18 de abril de 2017, de http://servicioskoinonia.org/relat/310.htm

García, J. (2014). La Educación Religiosa Escolar: área significativa del conocimiento. Acercamiento pedagógico a partir de la teología del pluralismo religioso. En J. Bonilla (director y editor), Educación religiosa escolar y pedagogías para el reconocimiento del pluralismo religioso (pp. 15-43). Bogotá: Universidad de San Buenaventura.

Geffré, C. (2001). El Auténtico desafío de la teología cristiana. Recuperado el 18 de abril de 2017, de http:// servicioskoinonia.org/relat/277.htm

Gómez, C. (2002). Psicología y religión. En F. Diez de Velasco y F. García (Eds.), El estudio de la religión (pp. 147-172). Madrid: Trotta.

Gómez, C. M. (2008). Diálogo interreligioso: el problema de su base común. Bogotá: Universidad del Rosario. Centro de Estudios Teológicos y de las Religiones.

Gómez, C. M. (2014). Las condiciones postseculares de la creencia religiosa. En C. Gómez (Ed.), La religión en la sociedad postsecular: transformación y relocalización de lo religioso en la modernidad tardía (pp. 17-63). Bogotá: Universidad del Rosario.

Guzmán, S. y Arias, Y. (2012). El pluralismo religioso en la región. Grafías Disciplinares de la UCP 17, 5-12.

Habermas, J. (2006). Entre naturalismo y religión. Barcelona: Paidós.

Hegel, G. W. (1984). Lecciones sobre filosofía de la religión. 1. Introducción y Concepto de religión. Madrid: Alianza.

Hick, J. (1990). Philosophy of religion. New Jersey, Englewood Cliffs: Prentice-Hall.

Hick, J. (2004). An Interpretation of Religion. Human Responses to the Transcendent. New York, N. Y.: Palgrave MacMillan.

Kolakowski, L. (1998). Si Dios no existe...: sobre Dios, el diablo, el pecado y otras preocupaciones de la llamada filosofía de la religión. Madrid: Tecnos.

Küng, H. (1989). Teología para la posmodernidad. Fundamentación ecuménica. Madrid: Alianza.

Ley 133 de 1994. Recuperado el 1 de noviembre de 2016, de http://www.alcaldiabogota.gov.co/sisjur/normas/ Norma1.jsp?i=331 
López, J. C. (2014). La educación religiosa escolar en Colombia: su enseñanza en un contexto pluralista y humanizante. Recuperado el 25 de julio de 2017, de http://ayura.udea.edu.co:8080/jspui/bitstream/123456789/608/1/PB0779.pdf

Mardones, J. M. (1994). Para comprender las nuevas formas de la religión. La reconfiguración postcristiana de la religión. Estella (Navarra): Verbo Divino.

Marzal, M. (2002). Antropología de la religión. En F. Diez de Velasco y F. García (Eds.), El estudio de la religión (pp. 121-146). Madrid: Trotta.

Mendieta, E. (2002). Sociología y religión. En F. Diez de Velasco y F. García (Eds.), El estudio de la religión (pp. 103-120). Madrid: Trotta.

Mendoza, A. y Velandia, G. (2013). La Educación Religiosa Escolar: un campo propicio para incentivar el pluralismo religioso desde la pedagogía intercultural. En J. Bonilla (director y editor), Reflexiones y perspectivas sobre Educación Religiosa Escolar (pp. 80-119). Bogotá: Universidad de San Buenaventura.

Ministerio de Educación Nacional. Decreto 4500 de 2006. Bogotá, Colombia. Recuperado el 1 de noviembre de 2016, de http://www.mineducacion.gov.co/1759/ articles-115381_archivo_pdf.pdf

Muñoz, J. F. (2014). La pedagogía del amor. Camino personal frente al paradigma unidad-pluralidad religiosa. En J. Bonilla (director y editor), Educación religiosa escolar y pedagogías para el reconocimiento del pluralismo religioso (pp. 217-275). Bogotá: Universidad de San Buenaventura.

Pardo, E. (2014). La pedagogía crítica en la perspectiva de Paulo Freire. Para el reconocimiento del pluralismo religioso en la Educación Religiosa Escolar. En J. Bonilla (director y editor), Educación religiosa escolary pedagogías para el reconocimiento del pluralismo religioso (pp. 111-158). Bogotá: Universidad de San Buenaventura.

Rawls, J. (1995). Liberalismo político. México: Fondo de Cultura Económica.

Rivera, F. (sin fecha). Liberalismo y laicidad. Recuperado el 7 de noviembre de 2016, de http://www.decidiresunderecho.org/files/fabiolariveracastro.pdf
Schmidt, T. M. (2014). Hacia un pluralismo razonable: la secularización y el futuro de la religión. En C. M. Gómez (Ed.), La religión en la sociedad postsecular: transformación y relocalización de lo religioso en la modernidad tardía (pp. 113-131). Bogotá: Universidad del Rosario.

Schwimmer, E. (1982). Religión y cultura. Barcelona: Anagrama.

Tobón, R. y Montoya, O. (2002). Proyecto de vida 5: valor del testimonio. Bogotá: Educar.

Tobón, R. y Montoya, O. (2004). Jardín católico: educación religiosa. Bogotá: Educar.

Torradeflot, F. (1998). La teología pluralista de las religiones. Recuperado el 17 de abril de 2017, de http: / / www.mercaba.org/FICHAS /Teologia/ la_teologia_pluralista_de_las_re.htm

Tschannen, O. (1991). The Secularization Paradigm: A Systematization. Journal for the Scientific Study of Religion, 30 (4), 395-415.

Uprimny, R. y Rodríguez, C. (2006). Constitución y modelo económico en Colombia: hacia una discusión productiva entre economía y derecho. Bogotá: Centro de Estudios de Derecho, Justicia y Sociedad, DeJuSticia.

Vigil, J. M. (2005). El actual debate de la Teología del Pluralismo después de la Dominus Iesus. En J. M. Vigil (Coord.), El actual debate de la Teología del Pluralismo después de la Dominus Iesus (pp. XX). Recuperado el 17 de septiembre de 2016, de http://www.servicioskoinonia.org/LibrosDigitales/LDK/LDK1.pdf

Vigil, J. M. (2007). El paradigma que viene. Reflexiones sobre la teología del pluralismo religioso. Revista iberoamericana de teología, (4), 55-72.

Vigil, J. M. (2012). Escritos sobre pluralismo. Cruzando la teología de la liberación con la teología del pluralismo religioso. Recuperado el 17 de abril de 2017, de http:// servicioskoinonia.org/LibrosDigitales/LDK/VigilEscritosSobrePluralismo.pdf

Weber, M. (1997). Sociología de la religión. Madrid: Istmo. 